Doi: $\underline{\text { dx.doi.org/10.17921/2525-5320.2016.150-154 }}$

\title{
RELATO DE EXPERIÊNCIA: UMA APRENDIZAGEM SIGNIFICATIVA EM LÍNGUA INGLESA POR MEIO DOS GÊNEROS TEXTUAIS: MÚSICA E BIOGRAFIA
}

\author{
Cristiane de Freitas* - UEL \\ Rosana Peres* - UEL
}

\section{INTRODUÇÃO}

O presente relato de experiência emergiu diante da necessidade de promover e desenvolver capacidades de reflexão e de argumentação para uma aprendizagem significativa ao educando de Língua Inglesa. A arte expressa a relação entre as formas sociais de uma cultura, interferindo na harmonia dos laços sociais, na sua ruptura ou no caos, presentes tanto na música, como na literatura e nas artes plásticas.

Dessa forma, aliada à necessidade de buscar-se novos caminhos que orientem a prática do processo de ensino-aprendizagem da Língua Inglesa, percebe-se que a música é uma das alternativas para auxiliar nas reflexões sobre temas, tais como, alcoolismo, drogas, entre outras, bem como no desenvolvimento da leitura, da oralidade e da escrita. Pois, a música é sempre uma atividade dinâmica que motiva os alunos.

Diante desse pressuposto o relato de experiência teve como suporte teórico o estudo dos gêneros textuais como instrumentos de ensino e aprendizagem dando ênfase ao gênero oral música e ao gênero escrito biografia que visa apresentar a pesquisa e os trabalhos realizados por meio do projeto de implementação pedagógica com o tema "Uma aprendizagem significativa em língua inglesa por meio dos gêneros textuais: música e biografia", desenvolvido com alunos do $2^{\circ}$ ano do Ensino Médio - Período Matutino do Colégio Estadual Antônio de Moraes Barros, $2^{\circ}$ bimestre do ano letivo de 2016.

*E-mail: cris_edf@hotmail.com

*E-mail: rosana71peres@gmail.com 
Estes gêneros foram escolhidos por atrair e envolver os alunos, servindo de motivação para uma aprendizagem significativa da língua em questão. A música estimula diferentes áreas do cérebro, aumenta a sensibilidade, a criatividade, a capacidade de concentração e fixação de dados. Além disso, resgata a cultura e ajuda na construção do conhecimento, e também é um excelente instrumento para promover a cidadania.

\section{DESENVOLVIMENTO}

\section{As ações desenvolvidas com os alunos}

Dessa maneira, para desenvolver este trabalho com os gêneros música e biografia buscou-se respaldo nos Parâmetros Curriculares Nacionais - PCN (BRASIL, 1998) e as Diretrizes Curriculares Estaduais do Ensino da Língua Inglesa - DCE - (PARANÁ, 2008), os quais nos orientam para que o ensino de língua seja trabalhado via gêneros textuais/discursivos.

A música, por ser um gênero textual que circula em vários ambientes, muitas vezes é grande motivadora para a aprendizagem de língua estrangeira, isto porque desperta a atenção e provoca curiosidade em conhecer o significado da letra da música. A música possui ainda a vantagem de ser um material que tem certa autenticidade, pois não sofre muitas alterações para tornar-se mais compreensível para os alunos. O gênero biografia do autor, também foi desafiador porque, para abordar de fato um resumo ligado à literatura, com o objetivo de introduzi-la ao universo textual do aluno, é preciso ter um conhecimento do contexto histórico das obras, da biografia do autor, dos temas referenciais da época, antes de aplicar qualquer estudo.

Diante do exposto, o objetivo geral foi trabalhar as quatro habilidades da língua Inglesa: "writing, listening, speaking e reading". Como objetivos específicos: discutir e analisar letras de músicas, principalmente, aquelas que apresentam mensagens implícitas e/ou explícitas de apologia ao alcoolismo, drogas, etc., propiciando, aos alunos, refletirem sobre essa forma de indução. Nesse sentido, foi propor um ambiente onde houvesse uma interação e participação dos alunos no processo de aprendizagem em língua inglesa, usando a função comunicativa dos gêneros, a reflexão sobre temas transversais cultura, preconceito, entre outros. 
Primeiramente, solicitou-se que trouxessem, para a aula uma letra de música de sua preferência (independente do tema). O objetivo, naquele momento, era sondar os diferentes gostos musicais. Na sequência, propiciou-se discussões sobre os temas supracitados, refletindo em relação aos aspectos culturais que a música suscita, a significação da mensagem que traz, bem como as consequências para a saúde e a sociedade, uma vez que promove a violência ao incentivar o uso abusivo do álcool, visando objetivos significativos no aprendizado da língua estrangeira correlacionada aos conhecimentos culturais e sociais.

Ao entender que a pesquisa favorece o processo ensino/aprendizagem, propiciou-se momentos de investigação, quando os alunos foram orientados a buscarem maiores informações sobre o gênero e, consequentemente, aumenta nossa responsabilidade como professor, pois cabe-nos ser mediadores do desenvolvimento sócio-cognitivo-histórico-cultural do aluno na escola. A escolha do grupo musical e cantor foi escolha dos próprios alunos mediante alguns critérios estabelecidos, tais como, sua importância no cenário cultural, suas influências de acordo com a época. Contudo, observou-se a preferência por bandas e cantores tradicionais como: Pink Floyd, Beatles, Elvis Presley, Bob Marley, até os mais contemporâneos como: Coldplay, Amy Winehouse e Lucas Graham e Michael Jackson.

Na sequência a metodologia aplicada foi uma concepção sociointeracionista aplicada dentro de uma língua, na qual propõe um trabalho que leve em consideração as diferentes funções sociais da linguagem, nada melhor do que levar para a sala de aula textos que circulam socialmente, pois reconhecemos, assim como Bakhtin (1992, p.261), que:

\begin{abstract}
O emprego da língua efetua-se em forma de enunciados (orais e escritos) concretos e únicos, proferidos pelos integrantes desse ou daquele campo da atividade humana. Esses enunciados refletem as condições específicas e as finalidades de cada referido campo não só por seu conteúdo (temático) e pelo estilo da linguagem, ou seja, pela seleção dos recursos lexicais, fraseológicos e gramaticais da língua, mas, acima de tudo, por sua construção composicional.
\end{abstract}

Ao trabalhar o gênero música, observou-se as dificuldades dos alunos em associar o som da palavra ouvida por eles à escrita. Em geral, nas escolas públicas, a prioridade linguística é voltada para o "writing", enquanto as demais habilidades 
(reading, speaking e listening) são postas em segundo plano. Nesse sentido, procurou-se trabalhar todas as habilidades, sendo a pesquisa acerca da biografia do cantor ou banda, pratica-se o "writing", ao buscar-se o momento histórico no mundo, no Brasil e suas Influências pratica-se o "reading", neste momento foi desenvolvido a interdisciplinaridade abordando os acontecimentos históricos ocorrido no ambiente e época na qual a determinada banda ou cantor se situava.

Ao desenvolver um estudo relacionado aos acontecimentos históricos, políticos e culturais da época abordada é proporcionado ao aluno um conhecimento crítico e reflexivo visando seu enriquecimento cultural. Ao escutar uma música, pratica-se o "speaking" e o "listening". Enfim, com este projeto de intervenção pôde-se ampliar plenamente uma aprendizagem significativa ao educando envolvendo todas as habilidades exigidas no conteúdo estruturante da Língua Inglesa. A proposta era aproximar-se das expectativas dos alunos, fazendo com que a língua aprendida fosse trabalhada na sua totalidade. No desenvolvimento do processo de aprendizagem da língua estrangeira observou-se que os alunos sentiram-se motivados para aprender. Ao final da atividade realizada observou-se maior interação entre os alunos e percebeu-se aumentar o interesse no estudo da língua inglesa bem como melhor desenvolvimento das habilidades da língua "reading, wirting, listening, speaking".

Diante do exposto, pode-se dizer que quando apropria-se de diferentes gêneros textuais o educando torna-se capacitado para estabelecer relações e fazer inferências em diversas situações de sua vida. E, cabe ao educador a tarefa de direcionar e mediar para que o educando adquira uma visão crítica e transformadora da realidade do qual está inserido.

\section{CONCLUSÃO}

O desenvolvimento dos gêneros "música" e "biografia" foi um tanto desafiador, porque trabalhar com música em uma outra língua requer prática e tempo, aspectos problemáticos que interferem no desenvolvimento dinâmico da aula. Ao entender-se a importância dos gêneros textuais como prática social e construção do sujeito, pensa-se no movimento dialético e dialógico, no qual a compreensão e a participação só acontecem quando somos sujeitos ativos neste processo, cabe ao 
educador fomentar uma prática que permita o desvelamento de realidades opressoras, que mantém os homens imersos na passividade.

Dessa forma, o projeto atingiu os objetivos, visto que, a aplicação dos gêneros música e biografia do autor em sala de aula chamou a atenção dos alunos e os fizeram perceber quantas coisas são possíveis aprender e discutir a partir de uma canção. Observou-se, também, que essa prática deve ser aplicada com mais frequência em sala de aula considerando os benefícios que esta pode proporcionar à aprendizagem dos estudantes, já que, os alunos participaram ativamente das atividades, pois o contexto musical e literário, bem como os debates realizados em sala tratavam de aspectos vividos por eles diariamente. Portanto, quando o assunto é voltado para a realidade do aluno, o diálogo e participação dos estudantes na execução das atividades torna-se uma ação prazerosa, de fácil compreensão e de envolvimento de toda a turma.

Dessa maneira pode-se dizer que, o professor, o aluno e o objeto de conhecimento, representado aqui pelo gênero música e o gênero biografia, se organizam para uma nova condição de produção do conhecimento, a fim de possibilitar ao educando desenvolver uma aprendizagem significativa compreendida como um processo de construção de significados.

\section{REFERÊNCIAS}

BAKHTIN, M. Marxismo e filosofia da linguagem. São Paulo: Hucitec,1992, p.261.

BRASIL. Secretaria de Educação Fundamental. Parâmetros curriculares nacionais: língua estrangeira. Brasília: MEC/SEF, 1998.

PARANÁ, Secretaria de Estado da Educação. Diretrizes curriculares de língua estrangeira moderna. Curitiba, 2008. 